\title{
Single versus dual orthogonal plating for comminuted midshaft clavicle fractures: a biomechanics study
}

\author{
Glenn N. Boyce ${ }^{1,2}$, Andrew J. Philpott', David C. Ackland ${ }^{3}$ and Eugene T. Ek ${ }^{1,4^{*}}$ (D)
}

\begin{abstract}
Background: Dual orthogonal plating of clavicle fractures may provide greater stiffness and strength than unilateral plate constructs and allow the use of lower-profile plates. We aim to biomechanically compare three clavicle plating constructs in a comminuted clavicle fracture model.

Method: Fifteen clavicle sawbones were osteotomised, simulating a comminuted midshaft fracture and allocated to either: group 1, single superior plate ( $3.5 \mathrm{~mm}$ superior plate); group 2, combination plating ( $3.5 \mathrm{~mm}$ superior plate, $2.8 \mathrm{~mm}$ anterior plate) and group 3, dual mini-plates (two 2.8-mm orthogonal mini-plates). Specimens were biomechanically tested under torsion and cantilever bending. Construct stiffness ( $\mathrm{Nm} /$ degree) and load to failure $(\mathrm{Nm})$ were measured.
\end{abstract}

Results: Group 2 had higher torsional ( 0.70 vs. $0.60 \mathrm{Nm} / \mathrm{deg}, p=0.017$ ) and cantilever bending stiffness ( 0.61 vs. $0.51 \mathrm{Nm} / \mathrm{deg}, p=0.025$ ) than group 1. Group 3 had lower cantilever bending stiffness (0.39 vs. $0.51 \mathrm{Nm} / \mathrm{deg}, p<$ 0.004 ) and load to failure ( 40.87 vs. $54.84 \mathrm{Nm}, p<0.01)$ than group 1. All dual plate constructs that catastrophically failed did so from fracture at the lateral ends of the plates. Single plate constructs failed due to plate bending.

Conclusion: Dual orthogonal fixation with mini-plates demonstrated lower stiffness and strength than traditional superior plating. The addition of an anterior mini-plate to a traditional superior plating improved construct stiffness and may have a role in patients seeking early return to activity.

Level of evidence: Basic science biomechanical study

Keywords: Clavicle, Fracture, Comminuted, Segmental, Biomechanical, Orthogonal, Internal fixation

\section{Introduction}

Clavicle fractures account for $2.6 \%$ of all fractures, of which $80 \%$ occur in the midshaft [1]. Midshaft clavicle fractures have historically been managed largely nonoperatively. More recently, a greater appreciation of symptomatic malunion and higher rates of non-union than initially reported has driven a trend toward more frequent

\footnotetext{
* Correspondence: eugene.ek@mog.com.au

'Melbourne Orthopaedic Group, 33 The Avenue, Windsor, Melbourne, VIC 3181, Australia

${ }^{4}$ Department of Surgery, Monash Medical Centre, Monash University, Melbourne, VIC, Australia

Full list of author information is available at the end of the article
}

operative intervention [2-5]. The optimal fixation construct is still debated.

Plate osteosynthesis is widely used for stabilisation of midshaft clavicle fractures. A variety of plates and placement locations have been described. The ideal construct would provide adequate stability to facilitate union, permit early return to work and sport and minimise hardware bulkiness and the need for subsequent removal procedures. Metalware prominence is the most frequent cause for reoperation, required in $9-68 \%$ of patients, followed by construct failure, requiring revision in 0 $16 \%$ of patients [6-12]. Plate bending, breakage and 
pull-out are recognised modes of plate failure [6-8]. Patients with comminuted injuries or those who return early to sport are at an increased risk $[6-8,13,14]$.

The use of dual orthogonal plating may provide greater multidirectional stiffness and strength than traditional superior plating techniques [15]. The benefit of dual plating may be twofold: firstly, improved strength may reduce construct failure, and secondly, stronger constructs may allow the use of minimally prominent low-profile plates. Allis et al. recently compared dual mini-plates to standard superior plates for midshaft clavicle fractures and found significantly fewer reoperations for metalware irritation in the dual mini-plate cohort [16]. Few biomechanical studies exist comparing these constructs.

We aimed to compare the strength and stiffness of traditional superior plating against two dual orthogonal plating constructs in a comminuted midshaft clavicle fracture model. Our hypothesis was that dual orthogonal plating would provide greater stiffness and strength than traditional single superior plating.

\section{Materials and methods}

\section{Specimen preparation}

Fifteen left-sided adult clavicle sawbones of identical size were prepared based on previously reported biomechanical studies (Model 3308 Sawbones Worldwide, Vashon WA) [15]. The midportion of each clavicle was osteotomised using one standardised thermoplastic guide to remove a 90-degree butterfly fragment of $2-\mathrm{cm}$ base, in order to represent inferior comminution or bone deficiency. Lack of bone to bone contact reduces the primary stability of the fracture and increases bending moments across the fixation construct.

Clavicle specimens were randomly allocated into three fixation groups that included the following:

- Group 1: single superior plate-Arthrex (Naples, FL, USA) 8-hole $3.5 \mathrm{~mm}$ (2.3 mm thickness) superior precontoured locking plate

- Group 2: combination plates-Arthrex (Naples, FL, USA) precontoured 8-hole $3.5 \mathrm{~mm}(2.3 \mathrm{~mm}$ thickness) locking plate positioned superiorly and Medartis (Basel, Switzerland) 10 hole $2.8 \mathrm{~mm}$ (1.6 $\mathrm{mm}$ thickness) olecranon locking plate positioned anteriorly

- Group 3: dual mini-plates-Medartis (Basel, Switzerland) 10-hole $2.8 \mathrm{~mm}$ (1.6 mm thickness) olecranon locking plates, one positioned superiorly and one positioned anteriorly

The two central holes of the precontoured $3.5-\mathrm{mm}$ plate and the single central hole of the $2.8-\mathrm{mm}$ miniplates were left empty. All other screw holes were filled with bicortical locking screws. Thermoplastic guides were used to ensure plate positioning was replicated between specimens. Digital callipers were used to measure the plate position from the medial and lateral end of the clavicle. In all specimens, the position was consistent.

\section{Biomechanical testing}

Each clavicle specimen was embedded in customised potting fixtures using dental cement and mounted to an Instron Materials Testing Machine (Instron, Model 3521, Parker Hydraulics) $[17,18]$. The sternal end of the clavicle was fixed to the lower crosshead of the Instron, while the acromial end was fixed to the upper crosshead (Fig. 1). The mechanical axis of the clavicle was positioned parallel with the vertical axis of the Instron.

The specimens were examined under torsion and cantilever bending [17]. Load rates were similar to those previously described [19]. Axial rotation was first tested by applying twisting motion about the longitudinal axis of the clavicle. An angular velocity of $0.5^{\circ} / \mathrm{s}$ was applied to the acromial end of the clavicle in the clockwise direction until $3^{\circ}$ of rotation was achieved. The clavicle was then unloaded by $3^{\circ}$ and a further loading of $3^{\circ}$ in the counterclockwise direction was applied. Pilot data demonstrated a highly linear rotational displacement with increasing torque $\left(R^{2}>0.99\right)$ until the point of failure. The chosen range was used to prevent disruption to the construct, while ensuring sufficient data to define the linear region of the torque-angle curve. Stiffness during torsion ( $\mathrm{Nm} /$ degree) was calculated from the gradient of the linear regression applied to each loaddeformation curve. The $R^{2}$ value was used as a measure of the goodness of the linear regression, and a minimum $R^{2}$ of 0.95 was applied for all stiffness calculations.

Three-point cantilever bending was then performed on all constructs to failure. Each clavicle was positioned horizontally, with the proximal clavicle fixture rigidly fixed. A support was placed just medial to the fracture site, $95 \mathrm{~mm}$ from the distal end of the clavicle, in order to apply stress to the fracture construct rather than generating large moments at the proximal potting fixture [19]. The Instron crosshead applied a vertical downward force upon the acromial end of the clavicle, at a rate of $0.5 \mathrm{~mm} / \mathrm{s}$. Stiffness during cantilever bending $(\mathrm{Nm} / \mathrm{de}-$ gree) was calculated from the gradient of the linear regression applied to each load-deformation curve. The $R^{2}$ value was used as a measure of the goodness of the linear regression, and a minimum $R^{2}$ of 0.95 was applied for all stiffness calculations. The bending moment $(\mathrm{Nm})$ was calculated by multiplying the magnitude of downward force by the force moment arm $(95 \mathrm{~mm})$. Load to failure $(\mathrm{Nm})$ was calculated as the bending moment which caused either $12^{\circ}$ of construct flexure (approximately $20-\mathrm{mm}$ vertical displacement) or the maximum 

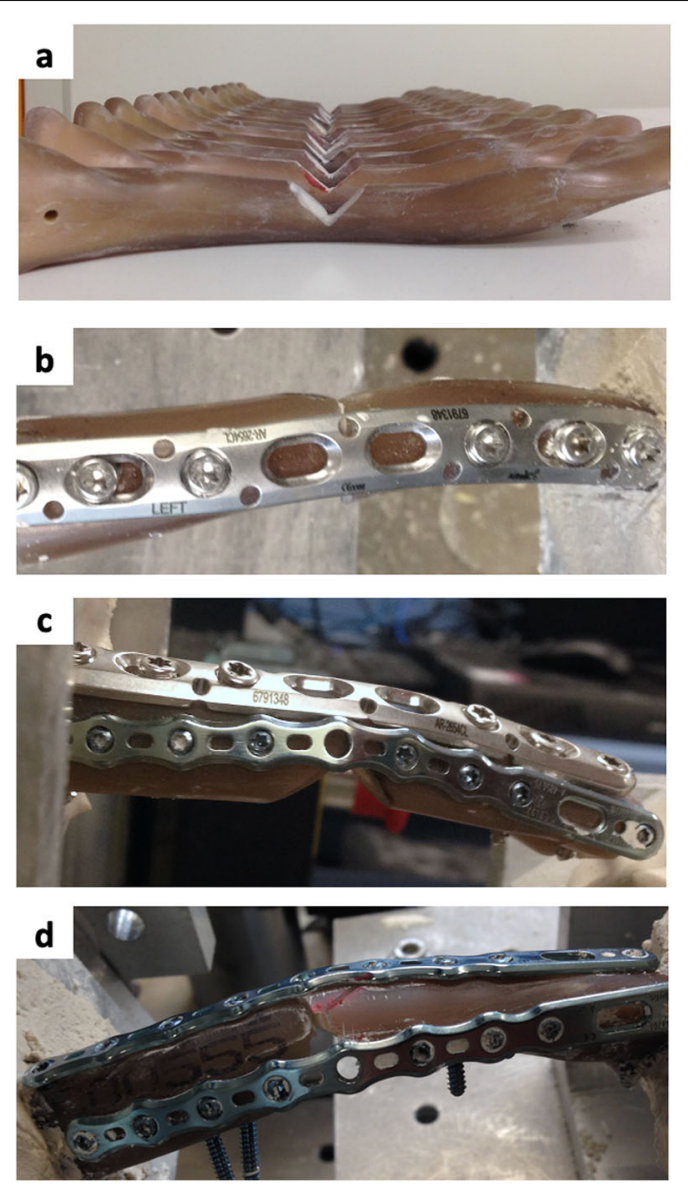

Fig. 1 a Synthetic clavicle sawbones with $2 \mathrm{~cm}$ segmental osteotomy. b Group 1, single superior plate fixation. c Group 2, combination plate fixation. d Group 3, dual mini-plate fixation. e Biomechanical testing under torsional load. f Testing under cantilever bending load

bending moment prior to catastrophic failure of the construct resulting in loss of bending resistance.

\section{Statistical analysis}

The Shapiro-Wilk test was used to assess data normality. A Levine's test was then used to assess whether equal variances existed between groups. A 1-way analysis of variance (ANOVA) was then used to evaluate betweengroup differences, and Bonferroni post hoc testing was employed. Significance level was set as $p<0.05$.

\section{Results}

\section{Torsional stiffness}

Under torsional loads, the combination plate construct (group 2) was significantly stiffer than the superior plate
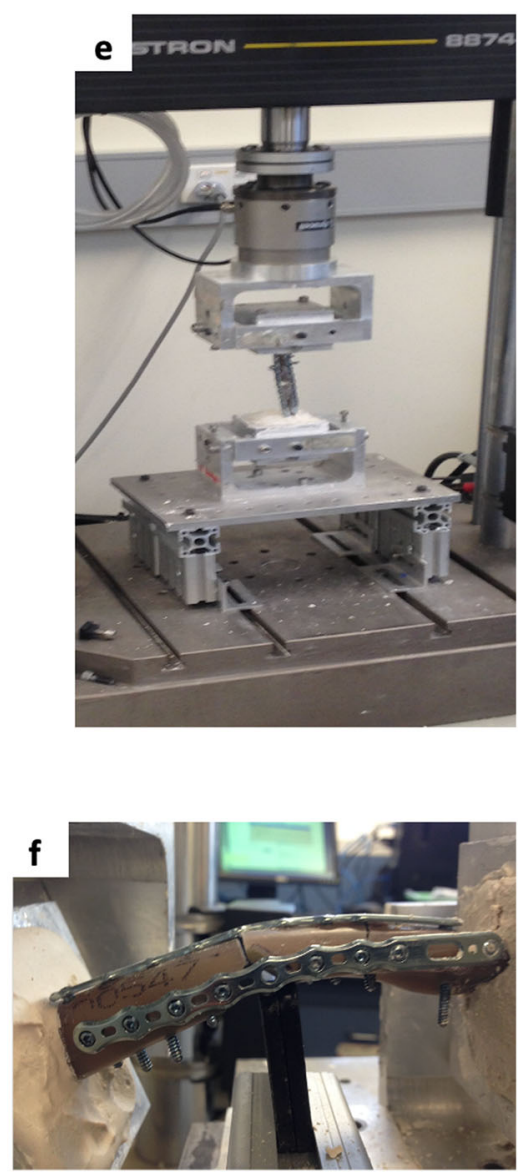

(group 1) (mean difference, $0.09 \mathrm{Nm} / \mathrm{deg} ; 95 \%$ CI $0.01-$ $0.17 ; p=0.017$ ) and dual mini-plate constructs (group 3) (mean difference, $0.15 \mathrm{Nm} / \mathrm{deg} ; 95 \%$ CI $0.07-0.23 ; p<$ 0.001) (Table 1). The superior plate was not significantly stiffer than the dual mini-plate construct (mean difference, $0.05 \mathrm{Nm} / \mathrm{deg} ; 95 \%$ CI 0.03-0.13; $p=0.291$ ).

\section{Cantilever bending stiffness}

Under cantilever bending loads, the combination plate construct was significantly stiffer than superior plate (mean difference, $0.09 \mathrm{Nm} / \mathrm{deg} ; 95 \%$ CI $0.01-0.18 ; p=0.025$ ) and dual mini-plate constructs (mean difference, $0.22 \mathrm{Nm} / \mathrm{deg}$; $95 \%$ CI $0.13-0.30 ; p<0.001)$. The superior plate was significantly stiffer than dual mini-plate construct (mean difference, 0.12; 95\% CI 0.04-0.21; $p=0.004$ ) (Fig. 2).

Table 1 Mean torsional stiffness, cantilever bending stiffness and load to failure of the fixation constructs

\begin{tabular}{llll}
\hline & Torsional stiffness (Nm/degree) & Cantilever bending stiffness (Nm/degree) & Cantilever bending load to failure $(\mathrm{Nm})$ \\
\hline Single superior plate & $0.60( \pm 0.08)$ & $0.51( \pm 0.01)$ & $54.84( \pm 5.18)$ \\
Combination plate & $0.70( \pm 0.06)$ & $0.61( \pm 0.05)$ & $60.78( \pm 7.41)$ \\
Dual mini-plate & $0.55( \pm 0.07)$ & $0.39( \pm 0.06)$ & $40.87( \pm 3.43)$ \\
\hline
\end{tabular}




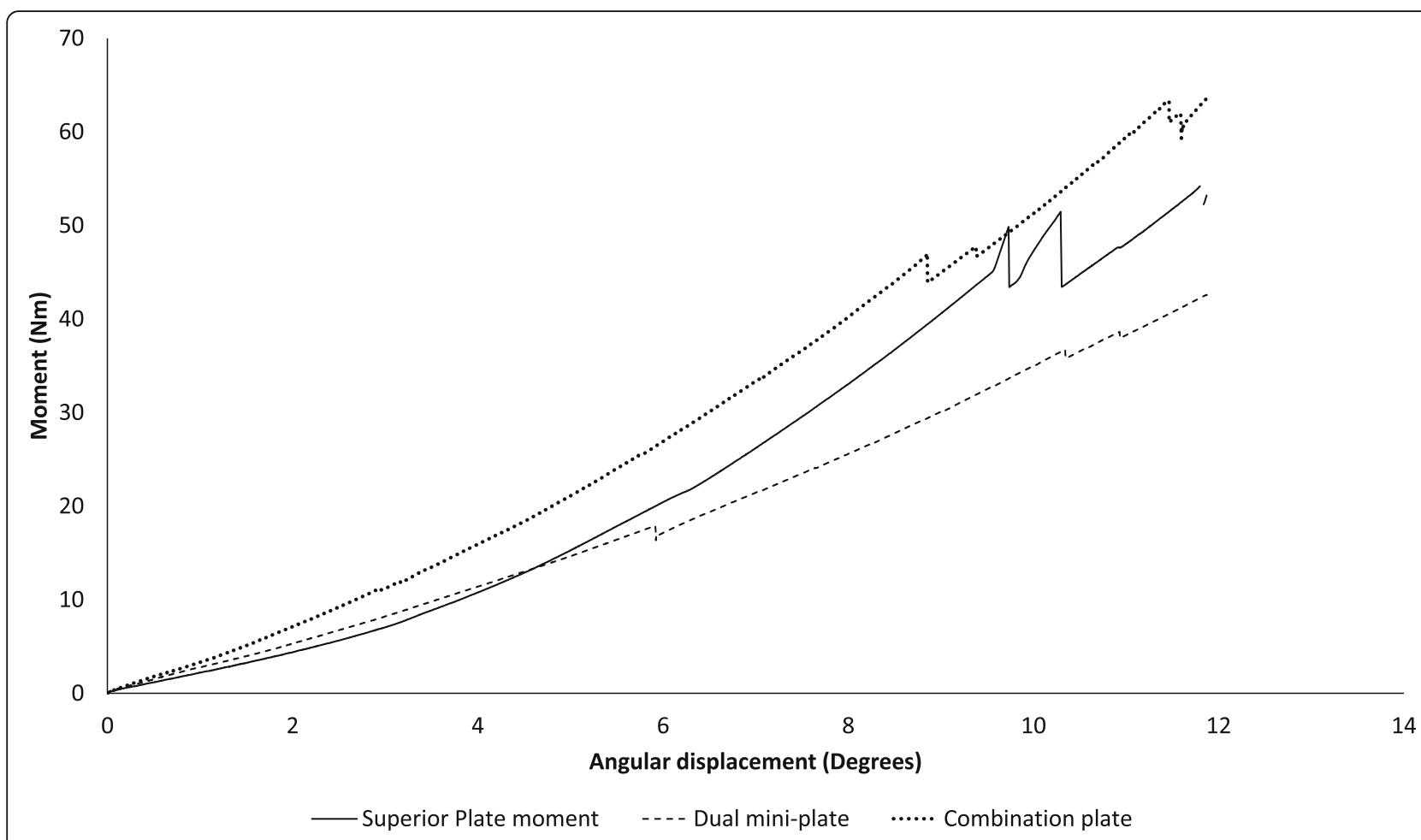

Fig. 2 Load-displacement curve displaying mean angular displacement occurring with each fixation construct under cantilever bending force

\section{Cantilever bending load to failure}

Under cantilever bending loads, the combination plate construct had significantly higher load to failure than dual mini-plate construct (mean difference, 19.91; 95\% CI $10.10-29.72 ; p<0.001)$, but not the superior plate construct (mean difference, 5.94; 95\% CI 3.87-15.76; $p=0.354$ ). The superior plate had significantly higher load to failure than the dual mini-plate construct (mean difference, 13.97; 95\% CI 4.16-23.78; $p=0.006$ ).

\section{Failures}

Five construct failures occurred before $12^{\circ}$ of displacement: in the superior plate group, two constructs failed through plate bending at the fracture site, in the combination plate group, two constructs failed through clavicle fracture at the most lateral screw hole and in the dual mini-plate group, one construct failed through clavicle fracture at the most lateral screw hole.

\section{Discussion}

This study compared two feasible orthogonal plating alternatives to traditional superior plate fixation in a comminuted midshaft clavicle fracture model. The addition of an anterior mini-plate to traditional superior plate fixation increased construct stiffness. In contrast, fixation with dual orthogonal mini-plates provided the lowest stiffness and strength, and our findings would caution its routine use.
Present challenges in clavicle fixation are implant prominence and fixation failure. An optimum construct would be minimally prominent, have adequate strength to resists the loads encountered and provide appropriate stiffness to facilitate fracture union. Construct failure has been reported through plate bending or pull-out, when the fracture is subject to excessive forces prior to union [6-8]. Risk factors for construct failure are comminuted fracture patterns [14], the use of plates as bridging constructs [13] and early return to sport [20]. One study reviewing professional athletes who returned to contact sport within 6 weeks of surgery reported a 33\% incidence of plate bending [20]. Dual orthogonal plating may reduce the incidence of construct failure and permit the use of low-profile plates to reduce metalware irritation.

Allis et al. reviewed 44 patients with midshaft clavicle fractures managed with either $3.5-\mathrm{mm}$ superior plating or dual mini-fragment plate fixation [16]. Reoperation rates were significantly lower in patients managed with dual mini-fragment plates than those managed with a $3.5-\mathrm{mm}$ superior plate, primarily due to less frequent metalware irritation ( $0 \%$ vs. $29 \%, p=0.008)$. All patients achieved union and no significant difference in functional outcomes was observed. The authors concluded that dual mini-fragment plate fixation is a viable treatment that may reduce reoperation with no compromise to clinical outcomes. 
Czajka et al. reviewed 81 patients with midshaft clavicle facture managed with dual mini-fragment plate fixation [21]. Three patients (4\%) required secondary surgery for soft tissue irritation, 2 (2\%) for infection and 1 (1\%) for mechanical failure. The authors concluded that dual mini-fragment plating resulted in excellent functional outcomes and low rates of symptomatic metalware, albeit at higher implant cost.

Few biomechanical studies exist comparing unilateral to orthogonal plating in clavicle fractures. Prasarn et al. undertook a clinical and biomechanical analysis of transverse clavicle fractures managed with dual mini-plates [15]. Dual mini-plate fixation with a superior $2.7-\mathrm{mm}$ plate and anteroinferior 2.4- $\mathrm{mm}$ plate were compared to traditional unilateral $3.5-\mathrm{mm}$ plate fixation in either a superior or anteroinferior position. Tested on sawbones, dual mini-plates had comparable stiffness to unilateral plating under axial and rotational loads. Under superiorinferior and anterior-posterior four-point bending loads, dual plating was more rigid than unilateral plating when the unilateral plate was stressed across its broad edge, but weaker than a unilateral plate stressed across its narrow edge. Seventeen patients were managed using the technique in a clinical setting and all achieved union, with no metalware removal procedures required. The authors concluded that dual mini-plating provided better multidirectional stability than single plate fixation, with excellent clinical outcomes and reduced incidence of metalware prominence requiring a second procedure.

Ziegler et al. compared dual mini-fragment plating to traditional unilateral plating in cadaver clavicles with a simulated inferior butterfly fragment [22]. No significant differences in stiffness or strength were observed between dual mini-fragment plating compared to traditional unilateral plating. The authors concluded that dual small-plate fixation is a viable option for midshaft clavicle fractures. This has been further supported by a recent finite element analysis study by Zhang et al. who demonstrated similar results [23].

The present study examined a sawbone clavicle fracture model with inferior comminution. We compared three constructs: traditional $3.5-\mathrm{mm}$ superior plating, traditional $3.5-\mathrm{mm}$ superior plating with an additional anterior mini-plate and dual mini-plating. Unilateral superior plating was chosen as a control because it is a widely utilised means of fixation and has been found biomechanically preferable to anterior plating in some studies [19, 24, 25]. Under cantilever bending, traditional superior plate fixation failed at $55 \mathrm{Nm}(577 \mathrm{~N}$ at $95 \mathrm{~mm})$. This is favourable to load to failure reported in prior studies: Celestre et al. reported failure at $36 \mathrm{Nm}(300 \mathrm{~N}$ at $120 \mathrm{~mm}$ ) with $3.5-\mathrm{mm}$ superior locking plates [19], Ziegler et al. reported failure at $20 \mathrm{Nm}(201 \mathrm{~N}$ at 100 $\mathrm{mm}$ ) with a $3.5-\mathrm{mm}$ superior plate [22], Smith et al. reported failure at $18 \mathrm{Nm}$ with a superior precontoured plate [26] and Drosdowech et al. reported failure through plate bending at 8 to $22 \mathrm{Nm}$ in a model with an inferior cortical defect [27]. We suspect differences in fixation constructs, clavicle models and testing methodology are likely the source of the substantial interstudy variation observed.

We then assessed the impact of adding an additional $2.8-\mathrm{mm}$ anterior mini-plate. The effect was to significantly increase construct stiffness without increasing load to failure. Finally, we tested dual mini-plating. Dual mini-plating provided the lowest stiffness and strength of all constructs. Similar to Zeigler et al.'s results, we found orthogonal plating constructs to fail due to clavicle fracture propagating from the final screw hole, in contrast to unilateral plating, which failed through plate bending. If orthogonal plating is to be used, we recommend staggering the plates to minimise the stress riser created.

It is unclear how strong clavicle fixation constructs need to be. Measuring the forces acting on the clavicle in vivo is challenging and therefore studies have relied on cadaveric testing and computational modelling. Taylor et al. used a computerised model and found the maximum forces experienced by the clavicle midshaft during eating were in a superior to inferior direction [28]. Hoogervorst et al. used the Delft shoulder and elbow model to estimate the load transmitted through the clavicle during activities of daily living [29]. The maximal force experienced was $97 \mathrm{~N}$, was compressive in nature and occurred during shoulder abduction. The model did not account for any items in the subject's hand or force applied through the hand during activity. Iannotti et al. assessed midshaft clavicle forces using a load cell mounted to 6 cadaveric clavicles and similarly found the greatest force to be an axial compressive force, occurring during shoulder abduction [24]. We surmise intermittent forces of far greater magnitude are experienced by patients during postoperative rehabilitation, particularly those who return early to sport or manual work.

The present study has a number of limitations. Firstly, this study used composite clavicle models that do not model the inhomogeneous anisotropic material properties of cortical and trabecular bone; however, synthetic clavicle models have been widely used in previous studies, closely replicate the properties of cadaver bone and minimise inter-specimen variability $[19,25,30-32]$. Failure of orthogonal plating constructs occurred through fracture of the composite bone at the final screw hole and it is unclear if this would be the case in a clavicle in vivo. Secondly, loading of clavicles was performed under unidirectional loading conditions. This provides interpretable results and permits interstudy 
comparison, however, may underestimate the multidirectional forces and ligamentous and muscular supports acting on the clavicle in vivo. Thirdly, cyclic loading and long-term integrity were not evaluated and therefore these findings reflect the immediate postoperative construct performance only. Finally, the clavicle fracture model tested had an inferior wedge defect, which represents 'worst case scenario' inferior comminution. In practice, reduction of inferior bony fragments or grafting to the defect would alter the biomechanical properties of fixation constructs.

\section{Conclusion}

The strength of the present study is that it compares two feasible orthogonal plating alternatives to traditional superior plate fixation in a comminuted midshaft clavicle fracture model. Our results do not support the routine use of dual mini-plates due to their lower stiffness and strength than traditional superior plate fixation. The addition of an anterior mini-plate to traditional superior plate fixation increased construct stiffness and may have value in patients seeking early return to activity.

\section{Abbreviations}

Nm: Newton metres; Deg: Degrees

\section{Acknowledgements}

The authors would like to acknowledge the Melbourne Orthopaedic Group Research Foundation for generously providing a grant for purchase of the bone models and use of the Instron Materials Testing Machine (Instron, Model 3521, Parker Hydraulics). Clavicle plates and screws used were generously provided by Medartis AG (Basel, Switzerland) and Device Technologies (Australia), who exercised no control over the conduct of this study

\section{Authors' contributions}

GB was involved in study design, experimentation, data analysis and manuscript preparation. AP was involved in manuscript preparation. DA was involved in study design, experimentation, data analysis and manuscript preparation. EE involved in study design and manuscript preparation. The authors read and approved the final manuscript.

\section{Funding}

Melbourne Orthopaedic Group Research Foundation Grant

\section{Availability of data and materials}

The datasets used and/or analysed during the current study are available from the corresponding author on reasonable request.

\section{Ethics approval and consent to participate}

Not applicable

\section{Consent for publication}

Not applicable

\section{Competing interests}

The authors declare that they have no competing interests.

\section{Author details}

${ }^{1}$ Melbourne Orthopaedic Group, 33 The Avenue, Windsor, Melbourne, VIC 3181, Australia. ${ }^{2}$ Department of Orthopaedic Surgery, Bendigo Health, Bendigo, VIC, Australia. ${ }^{3}$ Department of Biomedical Engineering, University of Melbourne, Melbourne, VIC, Australia. ${ }^{4}$ Department of Surgery, Monash Medical Centre, Monash University, Melbourne, VIC, Australia.
Received: 26 April 2020 Accepted: 30 June 2020

Published online: 09 July 2020

\section{References}

1. Postacchini F, Gumina S, De Santis P, Albo F. Epidemiology of clavicle fractures. J Shoulder Elb Surg. 2002;11(5):452-6.

2. Hill JM, McGuire MH, Crosby LA. Closed treatment of displaced middle-third fractures of the clavicle gives poor results. J Bone Joint Surg (Br). 1997;79(4): 537-9.

3. Huttunen TT, Launonen AP, Berg HE, Lepola V, Fellander-Tsai L, Mattila VM. Trends in the incidence of clavicle fractures and surgical repair in Sweden: 2001-2012. J Bone Joint Surg Am. 2016;98(21):1837-42.

4. McKee MD, Wild LM, Schemitsch EH. Midshaft malunions of the clavicle. J Bone Joint Surg Am. 2003;85(5):790-7.

5. Nowak J, Mallmin H, Larsson S. The aetiology and epidemiology of clavicular fractures. A prospective study during a two-year period in Uppsala, Sweden. Injury. 2000;31(5):353-8.

6. Canadian Orthopaedic Trauma S. Nonoperative treatment compared with plate fixation of displaced midshaft clavicular fractures. A multicenter, randomized clinical trial. J Bone Joint Surg Am. 2007;89(1):1-10.

7. Verborgt O, Pittoors K, Van Glabbeek F, Declercq G, Nuyts R, Somville J. Plate fixation of middle-third fractures of the clavicle in the semiprofessional athlete. Acta Orthop Belg. 2005;71(1):17-21.

8. Liu HH, Chang CH, Chia WT, Chen CH, Tarng YW, Wong CY. Comparison of plates versus intramedullary nails for fixation of displaced midshaft clavicular fractures. J Trauma. 2010;69(6):E82-7.

9. Bostman O, Manninen M, Pihlajamaki H. Complications of plate fixation in fresh displaced midclavicular fractures. J Trauma. 1997;43(5):778-83.

10. Wijdicks FJ, Van der Meijden OA, Millett PJ, Verleisdonk EJ, Houwert RM. Systematic review of the complications of plate fixation of clavicle fractures. Arch Orthop Trauma Surg. 2012;132(5):617-25.

11. Ferran NA, Hodgson P, Vannet N, Williams R, Evans RO. Locked intramedullary fixation vs plating for displaced and shortened mid-shaft clavicle fractures: a randomized clinical trial. J Shoulder Elb Surg. 2010; 19(6):783-9.

12. Kulshrestha V, Roy T, Audige L. Operative versus nonoperative management of displaced midshaft clavicle fractures: a prospective cohort study. J Orthop Trauma. 2011;25(1):31-8.

13. Meeuwis MA, Pull Ter Gunne AF, Verhofstad MH, van der Heijden FH. Construct failure after open reduction and plate fixation of displaced midshaft clavicular fractures. Injury. 2017:48(3):715-9.

14. Shin SJ, Do NH, Jang KY. Risk factors for postoperative complications of displaced clavicular midshaft fractures. J Trauma Acute Care Surg. 2012; 72(4):1046-50

15. Prasarn ML, Meyers KN, Wilkin G, Wellman DS, Chan DB, Ahn J, et al. Dual mini-fragment plating for midshaft clavicle fractures: a clinical and biomechanical investigation. Arch Orthop Trauma Surg. 2015; 135(12):1655-62

16. Allis JB, Cheung EC, Farrell ED, Johnson EE, Jeffcoat DM. Dual versus singleplate fixation of midshaft clavicular fractures. JBJS Open Access. 2020;5:2.

17. Ackland D, Griggs I, Hislop P, Wu W, Patel M, Richardson M. An intramedullary Echidna pin for fixation of comminuted clavicle fractures: a biomechanical study. J Orthop Surg Res. 2017;12(1):122.

18. Rawlings M, Knox D, Patel M, Ackland D. A hybrid approach to mid-shaft clavicle fixation. Injury. 2016:47(4):893-8.

19. Celestre P, Roberston C, Mahar A, Oka R, Meunier M, Schwartz A. Biomechanical evaluation of clavicle fracture plating techniques: does a locking plate provide improved stability? J Orthop Trauma. 2008;22(4):241-7.

20. Ricks M.W.S.; Boras, P.; Perret, M.; Hoy, G. When is early return too early? Clavicle plate fixation in Australian rules football athletes. BESS conference; Harrogate 2019.

21. Czajka CM, Kay A, Gary JL, Prasarn ML, Choo AM, Munz JW, et al. Symptomatic implant removal following dual mini-fragment plating for clavicular shaft fractures. J Orthop Trauma. 2017;31(4):236-40.

22. Ziegler CG, Aman ZS, Storaci HW, Finch H, Dornan GJ, Kennedy Ml, et al. Low-profile dual small plate fixation is biomechanically similar to larger superior or anteroinferior single plate fixation of midshaft clavicle fractures. Am J Sports Med. 2019;47(11):2678-85.

23. Zhang F, Chen F, Qi Y, Qian Z, Zi S, Zhong Z, Zhang X, Li D, Yu B. Finite element analysis of dual small plate fixation and single plate fixation for treatment of midshaft clavicle fractures. J Orthop Surg Res. 2020;15:148. 
24. Iannotti MR, Crosby LA, Stafford P, Grayson G, Goulet R. Effects of plate location and selection on the stability of midshaft clavicle osteotomies: a biomechanical study. J Shoulder Elb Surg. 2002;11(5):457-62.

25. Robertson C, Celestre P, Mahar A, Schwartz A. Reconstruction plates for stabilization of mid-shaft clavicle fractures: differences between nonlocked and locked plates in two different positions. J Shoulder Elb Surg. 2009;18(2):204-9.

26. Smith SD, Wijdicks CA, Jansson KS, Boykin RE, Martetschlaeger F, de Meijer PP, et al. Stability of mid-shaft clavicle fractures after plate fixation versus intramedullary repair and after hardware removal. Knee Surg Sports Traumatol Arthrosc. 2014:22(2):448-55.

27. Drosdowech DS, Manwell SE, Ferreira LM, Goel DP, Faber KJ, Johnson JA. Biomechanical analysis of fixation of middle third fractures of the clavicle. J Orthop Trauma. 2011;25(1):39-43.

28. Taylor PR, Day RE, Nicholls RL, Rasmussen J, Yates PJ, Stoffel KK. The comminuted midshaft clavicle fracture: a biomechanical evaluation of plating methods. Clin Biomech (Bristol, Avon). 2011;26(5):491-6.

29. Hoogervorst P, Bolsterlee B, Pijper M, Aalsma A, Verdonschot N. Forces acting on the clavicle during shoulder abduction, forward humeral flexion and activities of daily living. Clin Biomech. 2019;69:79-86.

30. Renfree T, Conrad B, Wright T. Biomechanical comparison of contemporary clavicle fixation devices. J Hand Surg [Am]. 2010;35(4):639-44.

31. Wang SH, Lin HJ, Shen HC, Pan RY, Yang JJ. Biomechanical comparison between solid and cannulated intramedullary devices for midshaft clavicle fixation. BMC Musculoskelet Disord. 2019;20(1):178.

32. Elfar J, Menorca RM, Reed JD, Stanbury S. Composite bone models in orthopaedic surgery research and education. J Am Acad Orthop Surg. 2014; 22(2):111-20,

\section{Publisher's Note}

Springer Nature remains neutral with regard to jurisdictional claims in published maps and institutional affiliations.

Ready to submit your research? Choose BMC and benefit from:

- fast, convenient online submission

- thorough peer review by experienced researchers in your field

- rapid publication on acceptance

- support for research data, including large and complex data types

- gold Open Access which fosters wider collaboration and increased citations

- maximum visibility for your research: over $100 \mathrm{M}$ website views per year

At $\mathrm{BMC}$, research is always in progress.

Learn more biomedcentral.com/submissions 